\title{
Management strategies for fibromyalgia
}

This article was published in the following Dove Press journal:

Open Access Rheumatology: Research and Reviews

I 2 July 201 I

Number of times this article has been viewed

\section{Kim Francis Le Marshall Geoffrey Owen Littlejohn}

Departments of Rheumatology and Medicine, Monash Medical Centre and Monash University, Victoria, Australia

Date of preparation: I 4 June 20II
Correspondence: Geoffrey Owen Littlejohn

Departments of Rheumatology and Medicine, Monash Medical Centre and Monash University, 246 Clayton Road, Clayton,Victoria 3168, Australia,

Tel +6I 395943565

Fax +6I 395643512

Email geoff.littlejohn@monash.edu
Clinical question: What are the effective, evidence-based strategies available for the management of fibromyalgia?

Conclusion: There are a number of management strategies available with robust evidence to support their use in clinical practice.

Definition: Fibromyalgia is a complex pain syndrome characterized by widespread, chronic muscular pain and tenderness, disordered sleep, emotional distress, cognitive disturbance, and fatigue. Its prevalence is estimated to be $3 \%-5 \%$ in the population and higher yet in patients with comorbid rheumatic diseases.

Level of evidence: Systematic reviews, meta-analyses, randomized controlled trials (RCTs).

Search sources: PubMed, Cochrane Library, manual search

Consumer summary: Key messages for patients and clinicians are:

1. There are many effective pharmacological management strategies available for fibromyalgia.

2. A nonpharmacological, multicomponent approach utilizing education, aerobic exercise, psychological therapy, and other strategies is also effective for fibromyalgia.

3. Despite the significant and, at times, disabling physical and psychological symptoms, fibromyalgia can be a manageable condition with a potentially good outcome.

Keywords: fibromyalgia, pain, treatment, management, evidence

\section{The evidence}

\section{What nonpharmacological strategies are effective? Education}

Level of evidence: RCT

Education alone may be beneficial in terms of self-efficacy, physical function, and quality of life..$^{1,2}$

\section{Exercise and related therapies}

Level of evidence: RCT, meta-analysis, systematic review

Aerobic exercise programs improve physical function, global well-being, fatigue, depressed mood, and health-related quality of life, and also help with pain reduction in fibromyalgia. ${ }^{3-5}$ One systematic review suggests that aerobic exercise should be land-based or water-based, of slight to moderate intensity, and undertaken two to three times per week. ${ }^{5}$ A graded and individualized approach to the intensity of the aerobic exercise undertaken is helpful, facilitating improved treatment adherence and fewer episodes of increased pain due to high intensity aerobic exercise. ${ }^{6}$ A meta-analysis of hydrotherapy ${ }^{7}$ demonstrates a similar reduction in pain and improved quality of life scores. Aerobic exercise (including hydrotherapy), in addition to education, may 
produce outcomes superior to education alone. Strength training has less overall evidence than aerobic exercise but may also reduce pain and improve physical function. ${ }^{8}$ Combined aerobic, strength, and flexibility exercises improve psychological health status and health-related quality of life scores. ${ }^{9}$ Combined strength and endurance training appears to improve strength, physical function, and other symptoms of fibromyalgia, such as fatigue. ${ }^{10}$ There is RCT evidence that tai-chi may be superior to education and stretching exercises alone on the Fibromyalgia Impact Questionnaire and for quality of life outcomes. ${ }^{11}$ Other strategies, such as yoga, mindfulness meditation, and Qijong movement therapy are also likely to be beneficial but have less evidence of additional benefit over education alone. ${ }^{12}$

\section{Psychological therapy}

Level of evidence: RCT, meta-analysis, systematic review Psychological therapies for fibromyalgia show much heterogeneity, making direct comparison of strategies difficult. Psychological therapies may produce improvements in pain, sleep, emotional distress, catastrophizing, and physical function, although results of trials are variable. ${ }^{13,14}$ Cognitive behavioral therapy has the most evidence, improving ability to cope with pain and health care-seeking behavior. ${ }^{15,16}$

\section{Multicomponent therapy}

Level of evidence: RCT, meta-analysis

Multicomponent therapy, including exercise, education, and cognitive behavioral therapy, improves pain, fatigue, depressive symptoms, quality of life, and physical fitness, although there is only evidence for sustained improvement (more than seven months) with physical fitness. ${ }^{17}$ Education combined with aerobic and flexibility exercises appears to be more effective than education alone, with greater improvements in pain, selfefficacy, physical function, and quality of life. ${ }^{2}$ There is RCT evidence for cognitive behavioral therapy producing modest additional improvement in physical function when combined with exercise and pharmacological therapy. ${ }^{18}$

\section{Repetitive transcranial magnetic stimulation}

Level of evidence: RCT

Repetitive transcranial magnetic stimulation of the motor cortex is thought to reduce pain by activating pain modulation pathways. A 21-week RCT of repetitive transcranial magnetic stimulation therapy in fibromyalgia showed significant improvements in pain and quality of life scores (fatigue, sleep, and morning lethargy). ${ }^{19}$ Further evidence is needed in this area.

\section{What pharmacotherapies are effective?}

\section{Drugs targeting central sensitization: gabapentin}

and pregabalin

Level of evidence: RCT, meta-analysis, systematic review Central sensitization is thought to play a key role in propagating fibromyalgia pain. ${ }^{20}$ Spinal cord dorsal neurons display enhanced excitability translating innocuous sensory input from mechanoreceptors into pain signals. ${ }^{21}$ This process is facilitated by the neurotransmitters, substance $\mathrm{P}$ and glutamate. Pregabalin and gabapentin ( $\alpha$-2-delta ligands) bind to the $\alpha$-2-delta subunit of the voltage-dependent calcium channels of dorsal neurons, reducing the release of substance $P$ and glutamate.

Three large meta-analyse ${ }^{22-24}$ indicate that pregabalin and gabapentin are effective in reducing pain, while improving sleep and health-related quality of life in fibromyalgia. Pregabalin has sustained outcomes to six months. ${ }^{25}$ There is more evidence for pregabalin overall, but no evidence of superiority to gabapentin. Pregabalin has similar efficacy at doses from $300 \mathrm{mg}$ up to $600 \mathrm{mg}$ daily and may cause more side effects (including dizziness and somnolence) at higher doses. For $\mathrm{a} \geq 30 \%$ pain reduction, the number needed to treat (NNT) is approximately seven, and for a $\geq 50 \%$ pain reduction, the NNT is closer to 10 . These pain outcomes have been shown to correlate with substantial improvements in "real world" outcomes, such as quality-adjusted life years and work attendance. ${ }^{26}$

\section{Drugs targeting the diffuse noxious inhibitory control system}

Tricyclic antidepressants: amitriptyline and cyclobenzaprine Serotonin norepinephrine reuptake inhibitors: milnacipran and duloxetine

Level of evidence: RCT, meta-analysis, systematic review

The diffuse noxious inhibitory control system helps to downregulate sensory input, including pain, via central descending antinociceptive pathways. ${ }^{27,28}$ It is thought to be dysfunctional in fibromyalgia due to reduced levels of the key neurotransmitters, serotonin and norepinephrine. Drugs that are able to increase the levels of these neurotransmitters are effective in the treatment of fibromyalgia.

Meta-analysis ${ }^{24}$ and systematic review ${ }^{29}$ of these agents shows that each is effective for pain reduction in fibromyalgia. Adjusted indirect comparison suggests that amitriptyline may be superior in this respect, but in the face of variable methodological quality and limited long-term data in the underlying RCTs, this finding is difficult to interpret. The NNT for $\mathrm{a} \geq 30 \%$ pain reduction is 3.54 for amitriptyline 
(95\% confidence interval [CI] 2.74-5.01), 8.21 for duloxetine (95\% CI 5.91-13.26), and 10.96 for milnacipran (95\% CI 8.27-16.26). Each agent may have a slightly different profile in terms of efficacy (Table 1). There are long-term data available for duloxetine ${ }^{30}$ and milnacipran ${ }^{31}$ but not for amitriptyline. Cyclobenzaprine also improves pain and sleep and has similar outcomes to amitriptyline in meta-analysis. ${ }^{32}$

\section{Tramadol}

Level of evidence: RCT

Apart from tramadol, there is no RCT evidence for use of opioid analgesia in fibromyalgia. Tramadol is an atypical opioid analgesic that also inhibits serotonin and norepinephrine reuptake, providing a plausible mechanism for it to be effective in treatment of fibromyalgia. There is RCT evidence ${ }^{33,34}$ that tramadol (with acetaminophen) produces improvement in the Fibromyalgia Impact Questionnaire and reduces pain, with $18 \%$ more than placebo achieving $\geq 30 \%$ pain reduction $(95 \% \mathrm{CI} 8 \%-28 \%, P<0.01 ; \mathrm{NNT}=5.5)$ and $16 \%$ more than placebo achieving $\geq 50 \%$ pain reduction $(95 \%$ CI $7 \%-26 \%, P<0.01 ; \mathrm{NNT}=6)$.

\section{Dopamine agonists}

Level of evidence: RCT

Dopamine is a centrally acting neurotransmitter that has effects on sleep, behavior, and the autonomic nervous system. Pramipexole, a dopamine agonist, produced improvement in pain, fatigue, and global function in one small 14-week RCT, in which $28 \%$ more than placebo achieved $\geq 50 \%$ pain reduction $(P=0.03$; NNT $=4) .{ }^{35}$ Further evaluation of pramipexole is warranted.

\section{Sodium oxybate}

Level of evidence: RCT

Sodium oxybate has a complex mechanism of action, including effects on sleep, and dopaminergic, noradrenergic, serotonergic, and glutaminergic neurons, ${ }^{36}$ potentially allowing for a therapeutic role in fibromyalgia. Sodium oxybate appears to improve sleep physiology on polysomnographic testing and to reduce pain and fatigue in fibromyalgia. ${ }^{37,38}$ Sodium
Table I Outcome profile for each agent in fibromyalgia

\begin{tabular}{llll}
\hline Outcome & Amitriptyline & Duloxetine & Milnacipran \\
\hline Pain & $\checkmark$ & $\checkmark$ & $\checkmark$ \\
Fatigue & $\checkmark$ & x & $\checkmark$ \\
Sleep & $\checkmark$ & $\checkmark$ & $\times$ \\
HRQOL & $x$ & $\checkmark$ & $\checkmark$ \\
\hline
\end{tabular}

$\checkmark$ indicates beneficial outcome; $x$ indicates no beneficial outcome. Abbreviation: HRQOL, health-related quality of life.

oxybate $4.5 \mathrm{~g}$ daily produced $\geq 30 \%$ pain reduction in $54.2 \%$ of patients (NNT $=6 ; 95 \%$ CI 4-12) while sodium oxybate $6 \mathrm{~g}$ daily produces $\geq 30 \%$ pain reduction in $58.5 \%$ (NNT $=5$; $95 \%$ CI 3-8). Prescription of sodium oxybate requires due care from the physician given its potential for abuse.

\section{Selective serotonin reuptake inhibitors}

Level of evidence: RCT

There is both supportive and contrary RCT evidence for the use of selective serotonin reuptake inhibitors, such as fluoxetine, in fibromyalgia. ${ }^{39-41}$ Overall, selective serotonin reuptake inhibitors appear to be less effective for pain reduction than other agents. Selective serotonin reuptake inhibitors that are highly selective for serotonin rather than serotonin and norepinephrine appear less effective in fibromyalgia (eg, citalopram). ${ }^{42}$ One $\mathrm{RCT}^{40}$ showed that fluoxetine reduces pain and improves the outcome on the Fibromyalgia Impact Questionnaire, but the placebo group had unusually poor outcomes, ${ }^{43}$ making interpretation difficult.

\section{Nonsteroidal anti-inflammatory drugs and opioid analgesia}

No RCT evidence supports the use of nonsteroidal antiinflammatory drugs or opioids other than tramadol in fibromyalgia.

\section{Serotonin (5-HT3) receptor antagonists}

Level of evidence: RCT

There is some limited RCT evidence showing that tropesitron, a serotonin (5-HT3) receptor antagonist, improves pain in fibromyalgia and may have a sustained effect. ${ }^{44,45}$ Further studies are warranted.

\section{The practice}

\section{Concurrent pharmacological}

\section{and nonpharmacological therapy}

The combination of pharmacological therapy with nonpharmacological strategies (education, exercise, and psychological therapy) seems rational. This may require the expertise of a physical therapist and psychologist in addition to the primary physician. Education should be provided by the physician, but can be supplemented by reputable online or written resources, and "help groups" may play a role also. Given the array of potentially beneficial management strategies 
available for fibromyalgia, individual review of each strategy (including adherence) is warranted in patients to ensure that each therapy is given an optimal trial and unhelpful therapies are adjusted.

\section{Multicomponent nonpharmacological therapy}

The combination of education, exercise, and cognitive behavioral therapy seems to produce superior outcomes to each individual strategy alone.

\section{Combination pharmacological therapy}

Despite limited evidence supporting combination pharmacological therapy in fibromyalgia, its use is commonplace and anecdotally it can improve symptoms. Empirically, combining therapies with different targets seems logical. An open-label RCT shows improved pain and Patient Global Impression of Change scores with the addition of milnacipran to pregabalin in patients with fibromyalgia not responding to pregabalin monotherapy. ${ }^{46}$ Obviously the potential benefits need to be weighed against potential side effects when considering combination pharmacological therapy. More trials are needed in this area. ${ }^{47}$

\section{Tailored pharmacological therapy}

Patients often require individualized drug regimens. Doses utilized may be restricted by side effects. Low initial doses followed by dose escalation may be helpful. In clinical practice, the dose required to produce a beneficial outcome may be lower than the dose commonly used in trials (eg, pregabalin $150 \mathrm{mg}$ daily may achieve a meaningful outcome for some patients with fibromyalgia).

\section{Adequate management of peripheral pain}

Analgesics, including nonsteroidal anti-inflammatory drugs and opioids, are helpful for management of peripheral paingenerating conditions, such as osteoarthritis, which may act as an additional peripheral pain stimulus and thereby augment central sensitization. ${ }^{48}$

\section{Potential pitfalls in management}

Appropriate initial evaluation and accurate diagnosis of fibromyalgia is crucial. In addition, an understanding that comorbid rheumatic, medical, and psychiatric conditions, including depression and anxiety, commonly coexist with fibromyalgia is important. These conditions need to be identified, evaluated and treated accordingly. Finally, an awareness of common drug side effects is invaluable, while remaining sentient of the very rare side effect of serotonergic syndrome, which may result from excess serotonin and norepinephrine reuptake inhibition.

\section{Disclosure}

Dr Littlejohn has done consulting work and has received honoraria from Pierre Fabre, Eli Lilly, and Pfizer.

\section{References}

1. Burckhardt CS, Mannerkorpi K, Hedenberg L, Bjelle A. A randomized, controlled clinical trial of education and physical training for women with fibromyalgia. J Rheumatol. 1994;21:714-720.

2. Rooks DS, Gautam S, Romeling M, et al. Group exercise, education, and combination self-management in women with fibromyalgia: A randomized trial. Arch Intern Med. 2007;167:2192-2200.

3. Busch AJ, Barber KA, Overend TJ, Peloso PMJ, Schachter CL. Exercise for treating fibromyalgia syndrome. Cochrane Database Syst Rev. 2007;4:CD003786

4. Kelley GA, Kelley KS, Hootman JM, Jones DL. Exercise and global well-being in community-dwelling adults with fibromyalgia: A systematic review with meta-analysis. BMC Public Health. 2010;10:198.

5. Hauser W, Klose P, Langhorst J, et al. Efficacy of different types of aerobic exercise in fibromyalgia syndrome: A systematic review and meta-analysis of randomised controlled trials. Arthritis Res Ther. 2010;12:R79.

6. van Santen M, Bolwijn P, Landewé R, et al. High or low intensity aerobic fitness training in fibromyalgia: Does it matter? J Rheumatol. 2002;29:582-587.

7. Langhorst J, Musial F, Klose P, Häuser W. Efficacy of hydrotherapy in fibromyalgia syndrome - a meta-analysis of randomized controlled clinical trials. Rheumatology (Oxford). 2009;48:1155-1159.

8. Busch AJ, Schachter CL, Overend TJ, Peloso PM, Barber KA. Exercise for fibromyalgia: A systematic review. J Rheumatol. 2008;35:1130-1144.

9. Sanudo B, Galiano D, Carrasco L, de Hoyo M, McVeigh JG. Effects of a prolonged exercise program on key health outcomes in women with fibromyalgia: A randomized controlled trial. J Rehabil Med. 2011;43:521-526.

10. Valkeinen H, Alen M, Hakkinnen A, Hannonen P, Kukkonen-Harjula K, Hakkinen K. Effects of concurrent strength and endurance training on physical fitness and symptoms in postmenopausal women with fibromyalgia: A randomized controlled trial. Arch Phys Med Rehabil. 2008;89:1660-1666.

11. Wang C, Schmid CH, Rones R, et al. A randomized trial of tai chi for fibromyalgia. $N$ Engl J Med. 2010;363:743-754.

12. Astin JA, Berman BM, Bausell B, Lee WL, Hochberg M, Forys KL. The efficacy of mindfulness meditation plus Qigong movement therapy in the treatment of fibromyalgia: A randomized controlled trial. J Rheumatol. 2003;30:2257-2262.

13. Thieme K, Flor H, Turk D. Psychological pain treatment in fibromyalgia syndrome: Efficacy of operant behavioural and cognitive behavioural treatments. Arthritis Res Ther. 2006;8:121-132.

14. Thieme K, Gracely RH. Are psychological treatments effective for fibromyalgia pain? Curr Rheumatol Rep. 2009;11:443-450.

15. Glombiewski JA, Sawyer AT, Gutermann J, Koenig K, Rief W, Hofmann SG. Psychological treatments for fibromyalgia: A metaanalysis. Pain. 2010;151:280-295.

16. Bernardy K, Fuber N, Kollner V, Hauser W. Efficacy of cognitivebehavioral therapies in fibromyalgia syndrome - a systematic review and metaanalysis of randomized controlled trials. $J$ Rheumatol. 2010;37:1991-2005.

17. Häuser W, Bernardy K, Arnold B, Offenbächer M, Schiltenwolf M. Efficacy of multicomponent treatment in fibromyalgia syndrome: A meta-analysis of randomized controlled clinical trials. Arthritis Rheum. 2009;61:216-224. 
18. Williams DA, Cary MA, Groner KH, Chaplin W, Glazer LJ, Rodriguez RM, Clauw DJ. Improving physical functional status in patients with fibromyalgia: A brief cognitive behavioral intervention. J Rheumatol. 2002;29:1280-1286.

19. Mhalla A, Baudic S, de Andrade DC, et al. Long-term maintenance of the analgesic effects of transcranial magnetic stimulation in fibromyalgia. Pain. 2011;152:1478-1485.

20. DeSantana JM, Sluka KA. Central mechanisms in the maintenance of chronic widespread noninflammatory muscle pain. Curr Pain Headache Rep. 2008;12:338-343.

21. Staud R. Evidence of involvement of central neural mechanisms in generating fibromyalgia pain. Curr Rheumatol Rep. 2002;4:299-305.

22. Hauser W, Bernardy K, Uceyler N, Sommer C. Treatment of fibromyalgia syndrome with gabapentin and pregabalin - a metaanalysis of randomized controlled trials. Pain. 2009;145:69-81.

23. Tzellos TG, Toulis KA, Goulis DG, et al. Gabapentin and pregabalin in the treatment of fibromyalgia: A systematic review and a meta-analysis. $J$ Clin Pharm Ther. 2010;35:639-656.

24. Roskell NS, Beard SM, Zhao Y, Le TK. A meta-analysis of pain response in the treatment of fibromyalgia. Pain Pract. December 28, 2010. [Epub ahead of print].

25. Crofford LJ, Mease PJ, Simpson SL, et al. Fibromyalgia relapse evaluation and efficacy for durability of meaningful relief(FREEDOM): A 6-month, double-blind, placebo-controlled trial with pregabalin. Pain 2008;136:419-431.

26. Moore RA, Straube S, Paine J, Phillips CJ, Derry S, McQuay HJ Fibromyalgia: Moderate and substantial pain intensity reduction predicts improvement in other outcomes and substantial quality of life gain. Pain. 2010;149:360-364.

27. Montoya P, Sitges C, Garcia-Herrera M, et al. Reduced brain habituation to somatosensory stimulation in patients with fibromyalgia. Arthritis Rheum. 2006;54:1995-2003.

28. Julien N, Goffaux P, Arsenault P, Marchand S. Widespread pain in fibromyalgia is related to a deficit of endogenous pain inhibition. Pain. 2005;114:295-302.

29. Häuser W, Petzke F, Üçeyler N, Sommer C. Comparative efficacy and acceptability of amitriptyline, duloxetine and milnacipran in fibromyalgia syndrome: A systematic review with meta-analysis. Rheumatology (Oxford). 2011;50:532-543.

30. Chappell AS, Littlejohn G, Kajdasz DK, Scheinberg M, D’Souza DN, Moldofsky H. A 1-year safety and efficacy study of duloxetine in patients with fibromyalgia. Clin J Pain. 2009;25:365-375.

31. Goldenberg DL, Clauw DJ, Palmer RH, Mease P, Chen W, Gendreau RM. Durability of therapeutic response to milnacipran treatment for fibromyalgia. Results of a randomized, double-blind, monotherapy 6-month extension study. Pain Med. 2010;11:180-194.

32. Arnold LM, Keck PEJ, Welge JA. Antidepressant treatment of fibromyalgia. A meta-analysis and review. Psychosomatics. 2000;4:104-113.

33. Bennett RM, Kamin M, Karim R, Rosenthal N. Tramadol and acetaminophen combination tablets in the treatment of fibromyalgia pain: A double-blind, randomized, placebo-controlled study. Am J Med. 2003;114:537-545.
34. Russell IJ, Kamin M, Bennett RM, Schnitzer TJ, Green JA, Katz WA. Efficacy of tramadol in treatment of pain in fibromyalgia. J Clin Rheumatol. 2000;6:250-257.

35. Holman AJ, Myers RR. A randomized, double-blind, placebocontrolled trial of pramipexole, a dopamine agonist, in patients with fibromyalgia receiving concomitant medications. Arthritis Rheum. 2005;52:2495-2505.

36. Maitre M. The gamma-hydroxybutyrate signalling system in brain: Organization and functional implications. Prog Neurobiol. 1997;51:337-361.

37. Moldofsky H, Inhaber NH, Guinta DR, Alvarez-Horine SB. Effects of sodium oxybate on sleep physiology and sleep/wake-related symptoms in patients with fibromyalgia syndrome: A double-blind, randomized, placebo-controlled study. J Rheumatol. 2010;37:2156-2166.

38. Russell IJ, Holman AJ, Swick TJ, Alvarez-Horine S, Wang YG, Guinta D. Sodium oxybate reduces pain, fatigue, and sleep disturbance and improves functionality in fibromyalgia: Results from a 14-week, randomized, double-blind, placebo-controlled study. Pain. 2011;152: 1007-1017.

39. Wolfe F, Cathey MA, Hawley DJ. A double-blind placebo controlled trial of fluoxetine in fibromyalgia. Scand J Rheumatol. 1994;23:255-259.

40. Arnold LM, Hess EV, Hudson JI, Welge JA, Berno SE, Keck PE, Jr. A randomized, placebo-controlled, double-blind, flexible-dose study of fluoxetine in the treatment of women with fibromyalgia. Am J Med. 2002;112:191-197.

41. Goldenberg D, Mayskiy M, Mossey C, Ruthazer R, Schmid C. A randomized, double-blind crossover trial of fluoxetine and amitriptyline in the treatment of fibromyalgia. Arthritis Rheum. 1996;39: 1852-1859.

42. Nørregaard J, Volkmann H, Danneskiold-Samsoe B. A randomized controlled trial of citalopram in the treatment of fibromyalgia. Pain. 1995;61:445-449.

43. Zijlstra TR, van de Laar MA. The lack of a placebo effect in a trial of fluoxetine in the treatment of fibromyalgia. Am J Med. 2002;113: 614.

44. Farber L, Stratz T, Bruckle W, et al. Efficacy and tolerability of tropisetron in primary fibromyalgia - a highly selective and competitive 5-HT3 receptor antagonist. Scand J Rheumatol Suppl. 2000;113:49-54.

45. Spath M, Stratz T, Neeck G, et al. Efficacy and tolerability of intravenous tropisetron in the treatment of fibromyalgia. Scand J Rheumatol. 2004;33:267-270.

46. Farmer M, Trugman JM, Wang Y, Gendreau RM. Effect of adding milnacipran to pregabalin for managing fibromyalgia: A randomized, open-label, controlled study. Abstract 648 presented at the annual scientific meeting of the American College of Rheumatology, November 7-11, 2010, Atlanta, GA.

47. Mao J, Gold MS, Backonja MM. Combination drug therapy for chronic pain: A call for more clinical studies. J Pain. 2011;12:157-166.

48. Staud R, Nagel S, Robinson ME, Price DD. Enhanced central pain processing of fibromyalgia patients is maintained by muscle afferent input: A randomized, double-blind, placebo-controlled study. Pain 2009;145:96-104
Open Access Rheumatology Research and Reviews

\section{Publish your work in this journal}

Open Access Rheumatology Research and Reviews is an international, peer-reviewed, open access journal, publishing all aspects of clinical and experimental rheumatology in the clinic and laboratory including the following topics: Pathology, pathophysiology of rheumatological diseases; Investigation, treatment and management of rheumatological

\section{Dovepress}

diseases; Clinical trials and novel pharmacological approaches for the treatment of rheumatological disorders. The manuscript management system is completely online and includes a very quick and fair peerreview system, which is all easy to use. Visit http://www.dovepress.com/ testimonials.php to read real quotes from published authors. 